\title{
REDESAIN MESIN PEMOTONG KERTAS TIPE PEMOTONGAN LURUS KAPASITAS 10 KG/JAM
}

\author{
Basori, Syafrizal dan Dwi Utomo Okta Priyana \\ Jurusan Teknik Mesin, Fakultas Teknik dan Sains, Universitas Nasional \\ e-mail : ory_banjarn@yahoo.com
}

\begin{abstract}
ABSTRAK
Dengan meningkatnya jumlah pemakaian kertas, tentunya meningkat pula jumlah limbah kertas yang dihasilkan setiap harinya. Limbah tersebut jumlahnya tidak sedikit, sehingga timbul masalah pemotongan yang kurang praktis. Hal tersebut perlu adanya penanganan khusus agar menjadisuatu produk yang mempunyainilai dan manfaat.Pada penelitian ini telah dilakukan perancangan sebuah mesin pemotong kertas dengan kapasitas produksi $10 \mathrm{~kg} / \mathrm{jam}$ yaitu meliputi perancangan bentuk, menentukan dimensi, pemilihan bahanserta menghitung gaya dan tegangan yang diizinkan. Untuk dapat menghasilkan mesin dengan kapasitas tersebut di perlukan data-data hasil perhitungan sebagai berikut : motor listrik dengan daya 450 Watt, 220Volt, 1 phase dengan kecepatan putaran $1400 \mathrm{rpm}$. Sebagai penerus daya dari motor ke reducer digunakan sabuk-V tipe-A sedangkan puli penggerak berdiameter $50 \mathrm{~mm}$ dan puli yang digerakkan $75 \mathrm{~mm}$ dengan perbandingan gearbox (speedreducer) 1 : 30.Rangka mesin dengan kapasitas $10 \mathrm{Kg} / \mathrm{jam}$ terbuat dari besi siku dengan dimensi $40 \times 40 \times 3 \mathrm{~mm}$ mampu menahan beban sebesar 250,155 N dengan nilai kelenturan sebesar 44,6 N/mm2, sedangkan tegangan lentur yang diizinkan untuk beban 250,155 $\mathrm{N}$ adalah sebesar $50 \mathrm{~N} / \mathrm{mm}^{2}$. Jadi rangka mesin dinyatakan aman dan layak untuk digunakan.
\end{abstract}

Kata kunci : mesin pemotong kertas, kapasitas, motor listrik, poros, puli, pasak, sabuk, speed reducer, bantalan, pisau penghancur.

\section{PENDAHULUAN}

\subsection{Latar Belakang}

Setiap orang berlomba untuk menciptakan suatu produk dengan harga murah, kualitas yang baik sehingga dapat berkompetisi di pasaran dengan produk-produk lain. Untuk mendapatkan suatu produk dengan harga murah dan berkualitas perlu adanya perancangan yang benar dan teliti agar diperoleh produk yang diharpakan.

Peralihan teknologi menuntut kita agar dapat meningkatkan standard kehidupan yang pada hakekatnya mengurangi ketergantungan pada negara lainsehingga mampu membuat produk sendiri. Salah satu dampak perkembangan ilmu pengetahuan dan teknologi adalah kecenderungan orang untuk menghemat waktu dan tenaga dalam memproduksi suatu barang.

Dalam memproduksi suatu barang, bahan baku produksi tidak harus baru, limbah onorganik juga bisa dijadikan sebagai bahan baku produksi yang mempunyai nilai ekonomis contoh yaitu limbah kertas yang sudah tidak terpakai.

Proses penghancuran kertas yang sudah tidak terpakai seperti dokumen-dokumen kantor, salah cetak dan lain-lain sangat dibutuhkan oleh instansi-instansi maupun perusahaan. Selain menghindari terjadinya penumpukan-penumpukan kertas yang hanya memenuhi ruangan juga tidak elok dipandang karena kertas tersebut sudah merupakan sampah.

Penanganan masalah limbah kertas sudah dilakukanya itu dengan memotong ukuran tertentu, namun kapasitas produksinya belum maksimal karena mesin hanya mampu memotong satu kertas dalam sekali proses.

Berdasarkan permasalahan tersebut, pada penelitian ini akan dilakukan perancangan dan pembuatan suatu mesin pemotong kertas yangmampu memproduksi dengan kapasitas yang lebih besar dari kapasitas mesin pemotong kertas yangsudah ada di pasaran. Dan hasil dari pemotongan kertas tersebut dapat dimanfaatkan menjadi paper scrap sebagai alas barang pecah belah, selain itu juga dapat didaur ulang menjadi bubur kertas untuk dijadikan bahan baku alternatif kertas.

\subsection{Tujuan Penelitian}

Tujuan merancang dan membuat mesin pemotong kertas tipe pemotongan lurus, yaitu meliputi :

a. Melakukan perhitungan data perancangan untuk memperoleh kapasitas $10 \mathrm{~kg} / \mathrm{jam}$ dengan jenis bahan uji kertas HVS A4 ukuran 210 x 297 $\mathrm{mm}$.

b. Merancang bentuk dan menentukan dimensi komponen-komponen mesin pemotong kertas. 
c. Memilihdan menentukan bahan yang sesuai kebutuhan.

d. Memilihdan menentukan bahan yang sesuai kebutuhan.

e. Menghitung gaya dan tegangan yang diizinkan pada komponen rangka mesin pemotong kertas.II.DASAR TEORI

\subsection{Mesin Pemotong Kertas}

Mesin pemotong kertas merupakan mesin yang berfungi sebagai alat pemotong kertas dengan hasil potongan sesuai rancangan (kebutuhan). Pada umumnya mesin pemotong kertas dapat dibedakan menjadi dua tipe pemotongan, yaitu pemotonganlurus (strip cut) dan potongan kecil (cross cut). Sumber tenaga penggerak yang digunakan adalah motor listrik, sedangkan sistem penyaluran tenaga menggunakan sistem transmisi puli. Mesin pemotong kertas ini di rancang berdasarkan mesinpemotong kertas yang sudah ada sebelumnya yang hanya mampu memotong kertas sebanyak satu lembar.

\subsection{Prinsip Kerja Mesin Pemotong Kertas}

Pada dasarnya prinsip kerja mesin pemotong kertas merupakan proses pemotongan kertas yang terjadi akibat perputaran kedua rol pemotong yang arahputarannya saling berlawanan. Adapun pemotongan dilakukan dengan cara memasukkan kertas diantara kedua rol (pisau pemotong) yang berbentuk pola alur melingkar.

\subsection{Komponen Utama Mesin Pemotong Kertas}

Mesin akan bekerja dengan baik jika komponen-komponen pendukung sesuai dengan spesifikasi rancangan. Komponen-komponen tersebut terdiri dari bagian-bagian yang memiliki fungsi dan kegunaan masingmasing.Bagian-bagian tersebut disusun menjadi satu kesatuan yang komplek dan mampu memenuhi kebutuhan sesuai yang diharapkan. Komponen-komponen mesin pemotong kertas tersebut meliputi :

\section{a. Motor}

Motor listrik dipilih sebagai penggerak mula karena dapat menghasilkan putaran tinggi. Motor yang digunakan adalah motor listrik AC 1 phase dengan daya 450 Watt, putaran $1400 \mathrm{rpm}$ dan frekuensi $50 \mathrm{~Hz}$.

\section{b. Puli dan Sabuk-V}

Puli digunakan untuk mentrasmisikan daya dari motor ke poros rol pemotong melalui gear box. Puli harus dipasang pada posisi yang sempurna agar sabuk dapat berputar pada permukaan puli. Puli biasanya terbuat dari besi tuang, baja tuang danalumunium. Puli yang terbuat dari besi mempunyai gaya gesek dan karakteristik penggunaan yang baik.

\section{c. Poros}

Sebagian besar poros digunakan pada mesin-mesin maupun peralatan yang melibatkan putaran, beban dan gaya. Oleh karena itu poros dianggap mampu dan memenuhi semua persyaratan umum yang biasanya muncul pada perancangan suatu alat. Hal-hal yang harus diperhatikan dalam perancangan poros adalah sebagai berikut :

1. Kekuatan Poros

Kekuatan poros dapat mengalami beban puntir dan lentur atau gabungan antara puntir dan lentur. Kemungkinan juga suatu poros mengalami beban tarik atau tekan seperti poros baling-baling kapal atau turbin.

2. Kekakuan Poros

Meskipun sebuah poros mempunyai kekuatan yang cukup, akan tetapi jika lenturan atas defleksi puntirnya terlalu besar akan mengakibatkan getaran dan suara sehingga mesin tidak dapat bekerja optimal.

3. Putaran Kritis

Putaran kritis terjadi apabila putaran mesin dinaikkan pada saat harga tertentu dapat mengakibatkan getaran yang luar biasa, maka poros harus direncanakan sedemikian rupa hingga putaran kerja lebih rendah daripada putaran kritisnya.

4. Korosi

Bahan-bahan yang tahan akan korosi perlu dipilih dan menjadi prioritas utama dalam perancangan poros yang berkontak langsung dengan fluida atau bahan-bahan korosif.

5. Bahan Poros

Poros untuk mesin biasanya dibuat dari material baja. Baja karbon konstruksi mesin (disebut bahan S-C) yang dihasilkan dari bahan ingot, meskipun demikian bahan ini kekerasannya agak kurang dan tetap akan mengalami deformasi karena tegangan yang kurang seimbang.

\section{d. Kopling Fleksibel}

Kopling fleksibel merupakan suatu komponen mesin yang digunakan untuk menyatukan (menghubungkan atau 
melepaskan) dua unit poros dengan tujuan untuk mentransmisikan daya mekanis dari motor ke rol pemotong. Penggunaan kopling fleksibel bertujuan untuk membuat fleksibilitas mekanis, mengurangi transmisi dari beban kejut, melakukan perlindungan terhadap beban lebih dan mengubah karakteristik getaran unit yang berputar.

\section{e. Pasak/Baut Pengikat}

Pasak merupakan salah satu komponen yang berfungsi sebagai pengunci yang disisipkan diantara poros agar keduanya tersambung dengan pasti sehingga mampu meneruskan momen putar/torsi.

\section{f. Dudukan / Bantalan}

Dudukan rol pemotongadalah elemen yang mampu menumpu poros berbeban, sehingga putaran atau gerakan bolakbaliknya dapat berlangsung secara halus dan aman.

Dudukan rol pemotong harus cukup kokoh untuk memungkinkan poros serta elemen mesin lainnya bekerja dengan baik.

\section{g. Rangka}

Rangka mesin pemotong kertas ini terbuat dari besi siku dengan ukuran $40 \mathrm{x}$ $40 \mathrm{~mm}$. Rumus-rumus yang digunakan dalam merancang konstruksi rangka mesin pemotong kertas diuraikan sebagai berikut.

Massa pada rangka dapat dihitung dengan rumus :

$$
\mathrm{W}=\mathrm{m} \times \mathrm{g}
$$

Gaya tumpuan RA dan RB dapat dihitung dengan rumus :

$(\mathrm{I} 1+\mathrm{I} 2)$

$$
\mathrm{RB} .(\mathrm{I} 1+\mathrm{I} 2+\mathrm{I} 3)=(\mathrm{W} 1 . \mathrm{I} 1)+\mathrm{W} 2 \text {. }
$$

$$
\mathrm{RA}=(\mathrm{W} 1+\mathrm{W} 2)-\mathrm{RB}
$$

Momen dititik A, B, C, D dapat dihitung dengan rumus :

$$
\begin{aligned}
& \Sigma \mathrm{MA}=0 \\
& \Sigma \mathrm{MB}=0 \\
& \mathrm{MC}=\mathrm{RA} . \mathrm{I} 1 \\
& \mathrm{MD}=\mathrm{RB} . \mathrm{I} 3
\end{aligned}
$$

Tegangan lentur pada rangka dapat dihitung dengan rumus :

$$
\sigma=\frac{m}{I_{0}}
$$

Tegangan lentur yang diizinkan dapat dihitung dengan rumus :

$$
\sigma_{a}=\frac{\sigma b}{s f 1 x s f^{2}}
$$

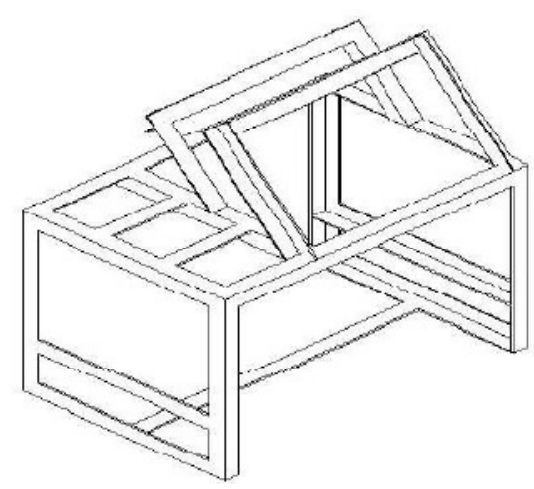

Gambar 1. Konstruksi rangka

\section{METODOLOGI PENELITIAN}

Dalam proses perancangan dan pembuatan mesin pemotong kertas tipe pemotongan lurus di perlukan tahapan-tahapan seperti terlihat pada gambar dibawah ini.

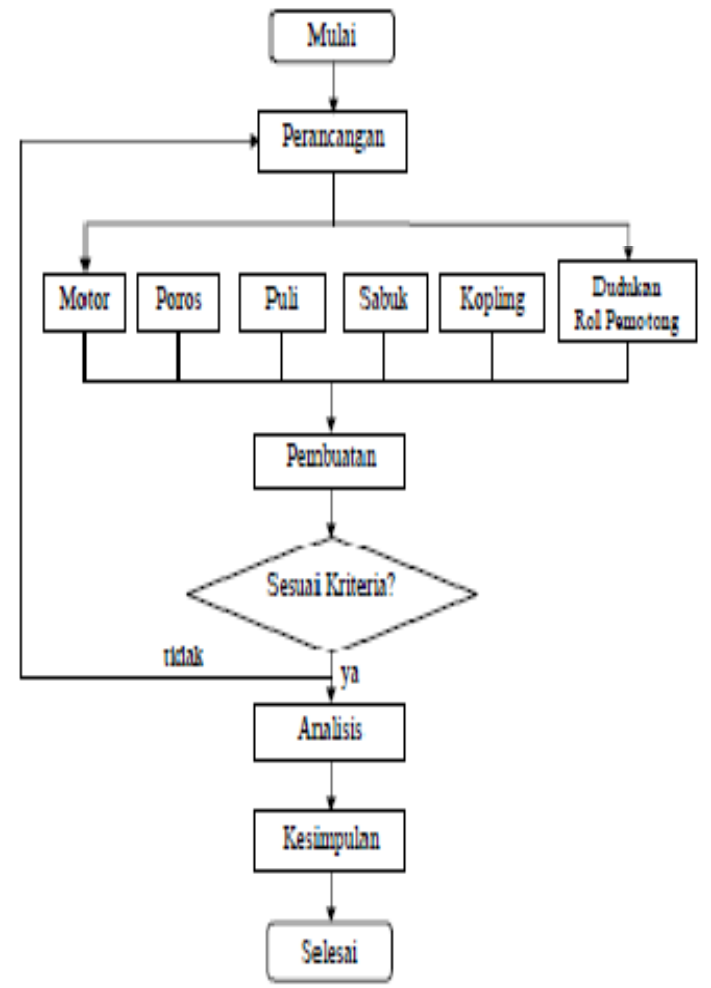

Gambar 2. Diagram alir proses perancangan dan pembuatan

\subsection{Motor Listrik}

Dalam perancangan mesin pemotong kertas ini penggerak mula yang digunakan yaitu motor listrik. Daya yang dihasilkan akan mengakibatkan poros berputar, selanjutnya 
putaran tersebut ditransmisikan ke gear box melalui sabuk-V.

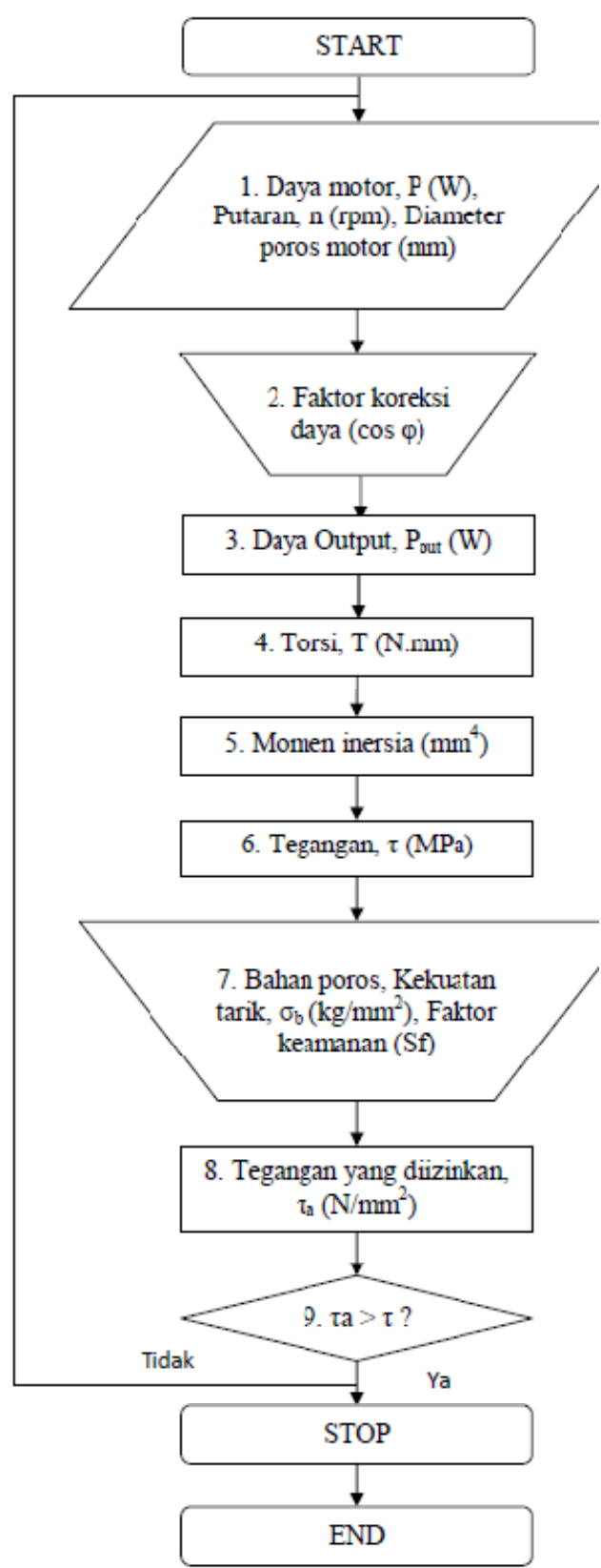

Gambar 3. Diagram alir perencanaan motor listrik

\section{a. Puli dan Sabuk}

Puli yang digunakan terbuat dari bahan alumunium dan sabuk yang digunakan adalah sabuk-V dengan tipe A. Perencanaan puli dan sabuk dijelaskan seperti berikut ini.

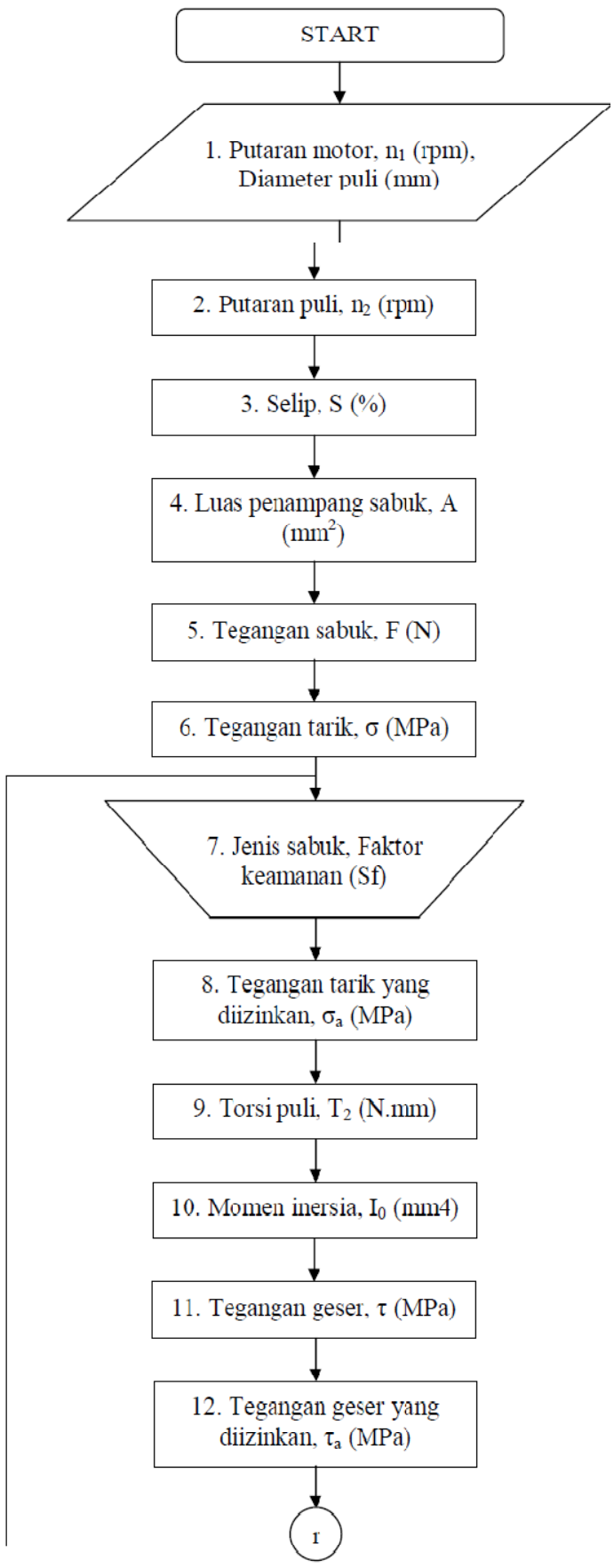




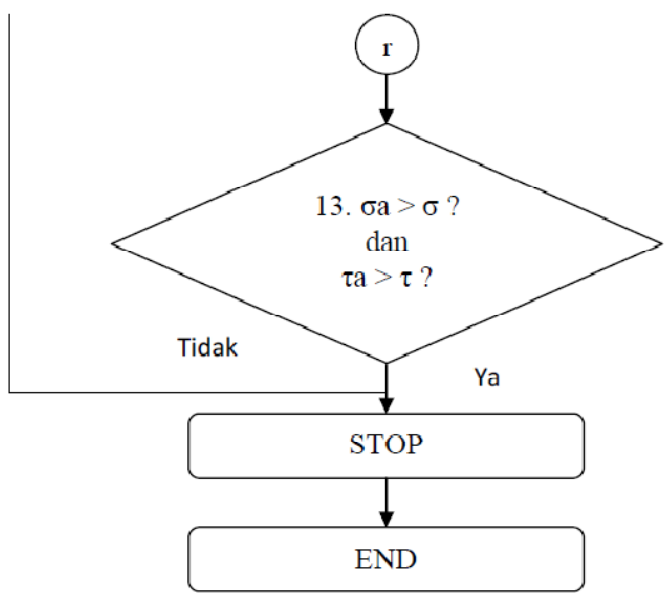

Gambar 4. Diagram alir perencanaan puli dan sabuk

\section{b. Kopling Fleksibel}

Kopling fleksibel adalah suatu elemen mesin yang menghubungkan poros penggerak denganporos yang digerakkan. Perencanaan kopling fleksibel dibahas seperti berikutini.

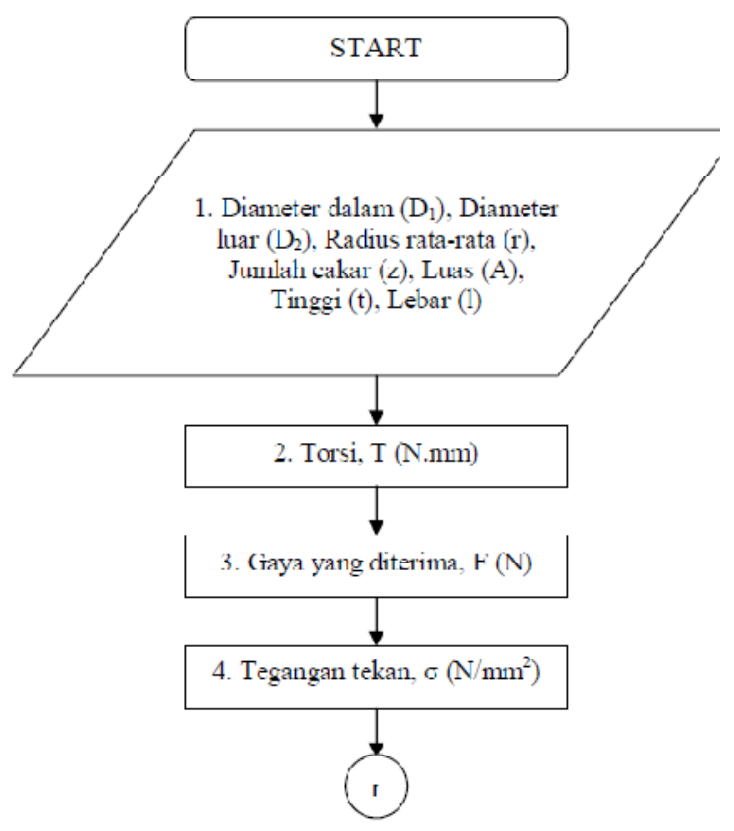

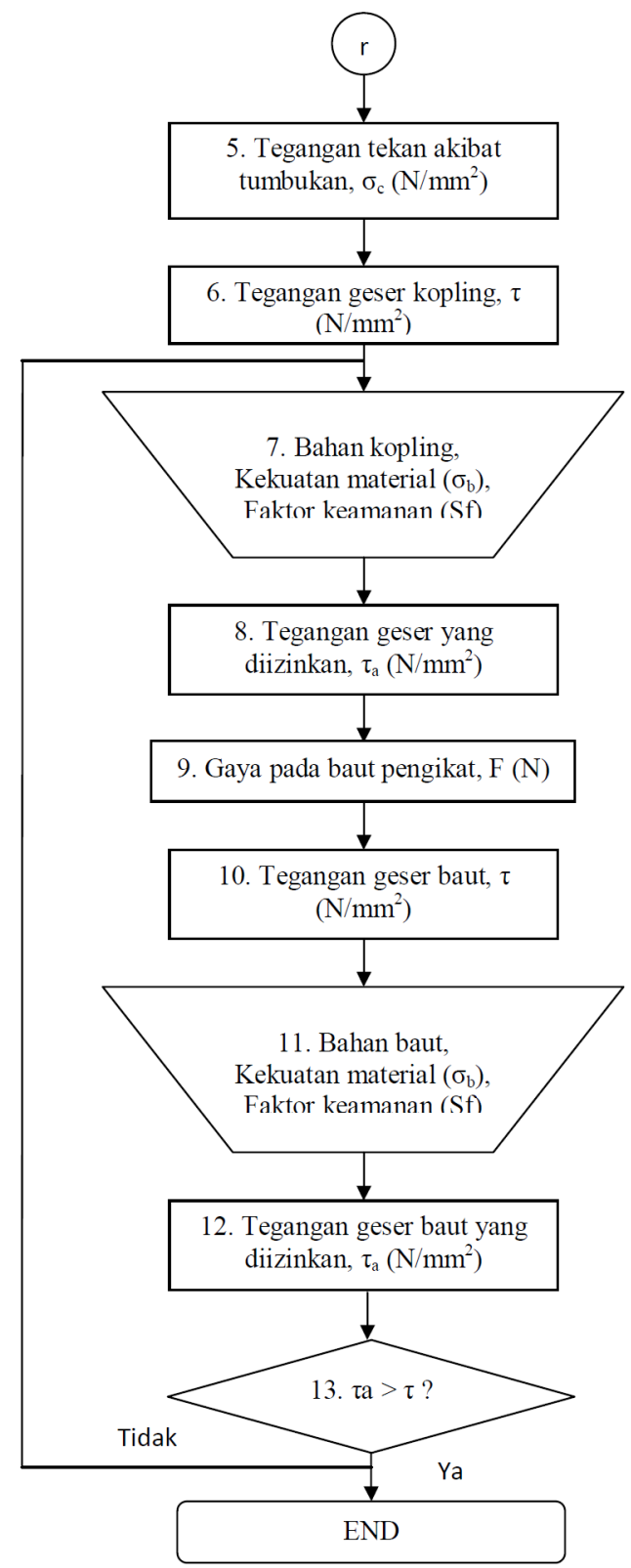

Gambar 5. Diagram alir perencanaan kopling 


\section{c. Roll Pisau Pemotong}

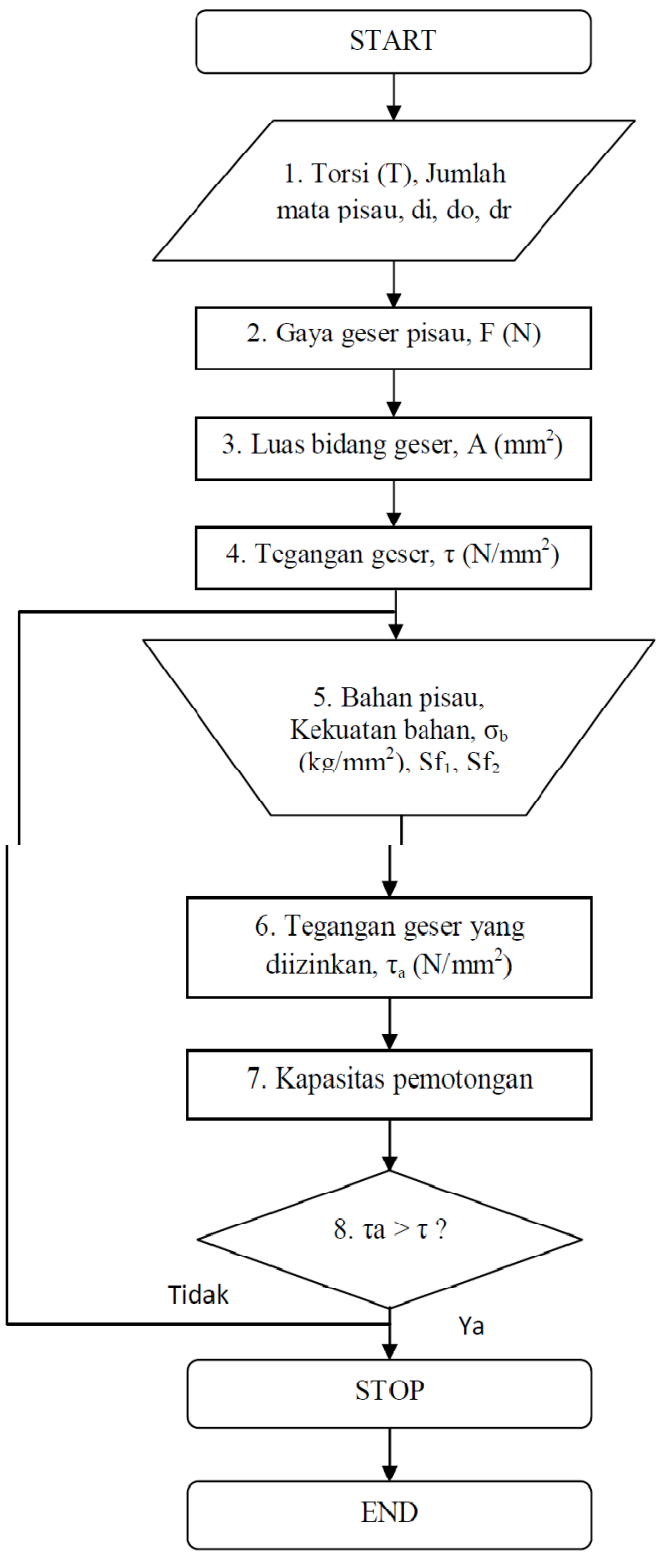

Gambar 6. Diagram alir perencanaan rol pisau pemotong

\section{d. Dudukan/Bantalan}

Dudukan rol pemotong merupakan komponen mesin yang digunakan untuk menahan atau menopang elemen-elemen mesin lainnya, untuk itu dalam perancangan dudukan poros rol (mata pisau) mesin penghancur kertas menggunakan dudukan persegi panjang. Dimensi dari dudukan ini ditentukan berdasarkan perancangan poros yang telah dilakukan.
Berikut ini adalah tahapan perencanaan dan spesifikasi dari dudukan rol pemotong.

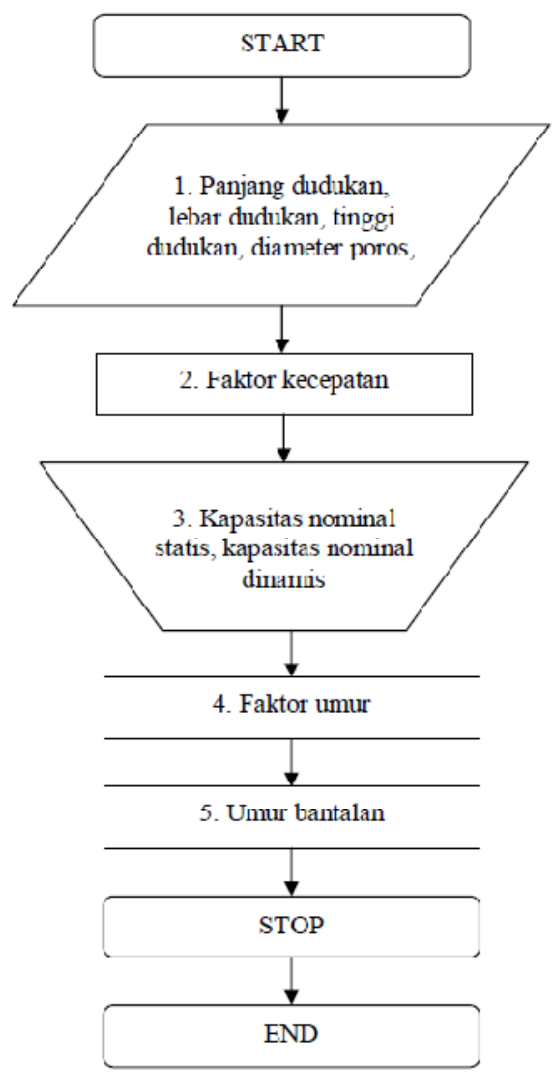

Gambar 7. Diagram alir perencanaan bantalan

\section{e. Rangka}

Rangka mesin pemotong kertas ini terbuat dari besi siku dengan ukuran $40 \mathrm{x}$ $40 \mathrm{~mm}$. Perencanaan rangka mesin dapat dilihat pada diagram alir dibawah ini. 


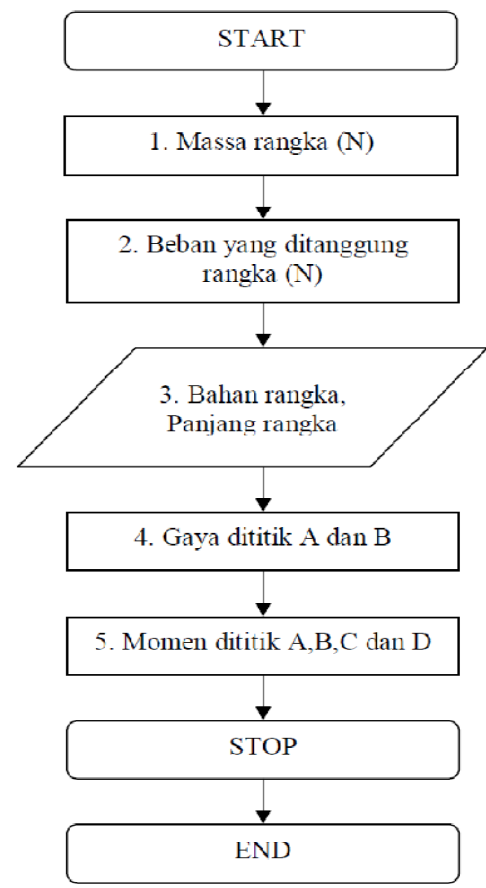

Gambar 8. Diagram alir perencanaan rangka

\section{HASIL DAN PEMBAHASAN}

\subsection{Hasil Perhitungan}

Berdasarkan data hasil perancangan dan pembuatan mesin pemotong kertas, maka diperoleh hasil perhitungan untuk menentukan dimensi dari masing-masing komponen, hasil yang telah diperoleh yaitu sebagai berikut :

\section{a. Motor Listrik}

Daya yang dihasilkan oleh motor untuk menggerakan puli, gear box dan poros rol pemotong adalah sebesar $405 \mathrm{~W}$, torsi yang dihasilkan dari daya motorsebesar 2760 N.mm. Tegangan yang diizinkan pada poros motor sebesar $47,3 \mathrm{~N} / \mathrm{mm} 2$, sedangkan tegangan yang dihasilkan pada poros motor sebesar 2,05 MPa, maka perencanaan pemakaian motor dinyatakan aman.

\section{b. Puli dan Sabuk}

Sabuk yang digunakan untuk perancangan mesin pemotong kertas menggunakan jenis sabuk-v tipe A dengan bahan karet dan digunakkan puli dengan diameter puli penggerak sebesar $50 \mathrm{~mm}$ dan puli yang digerakkan $75 \mathrm{~mm}$. Dari perbandingan puli tersebut, putaran motor yang semula $1400 \mathrm{rpm}$ berubah menjadi 933,33 rpm. Karena adanya faktor nilai koreksi, maka putaran diasumsikan sebesar $900 \mathrm{rpm}$.

\section{c. Gear Box}

Jenis gear box yang digunakan untuk menurunkan kecepatan putaran motor adalah WPA 60 dengan perbandingan ratio, $i=1: 30$. Jadi kecepatan putaran dari motor yang sudah terkoreksi sebesar $900 \mathrm{rpm}$ direduksi menjadi $30 \mathrm{rpm}$.

\section{d. Kopling Fleksibel}

Jenis kopling yang digunakan dalam perancangan mesin pemotong kertas adalah kopling cakar. Kopling ini mempunyai jumlah cakar sebanyak 5 buah, dengan ukuran tinggi cakar $15 \mathrm{~mm}$ dan lebar cakar $10 \mathrm{~mm}$. Gaya yang diterima pada masing-masing cakar kopling sebesar 598,5 N. Tegangan geser yang diizinkan pada kopling sebesar $8,829 \mathrm{~N} / \mathrm{mm} 2$, sedangkan tegangan geser yang dihasilkansebesar 2,3 N/mm2, maka perencanaan kopling fleksibel dinyatakan aman.

\section{e. Dudukan / Bantalan}

Dudukan yang digunakan terbuat dari bahan baja dengan dimensi panjang 105 $\mathrm{mm}$, lebar $25 \mathrm{~mm}$, dan tinggi $60 \mathrm{~mm}$, diameter lubang poros $20 \mathrm{~mm}$, kapasitas nominal dinamis sebesar $1000 \mathrm{~N}$, kapasitas nominal statis sebesar $635 \mathrm{~N}$. Dari data tersebut maka diperoleh faktor kecepatan sebesar 1,03 dan faktor umur 1,62. Jadi dudukan tersebut dapat layak pakai selama 51016,8 jam. Tegangangeser yang diizinkan pada dudukan sebesar $86,1 \mathrm{~N} / \mathrm{mm} 2$ sedangkan tegangan geser yang dihasilkan sebesar 79,1 MPa, maka perencanaan dudukan dinyatakan aman.

\section{f. Rangka}

Jenis rangka yang dipergunakan adalah besi siku dengan dimensi 40 x $40 \mathrm{~mm}$. Beban yang diterima rangka adalah sebesar $\mathrm{W} 1=176,68 \mathrm{~N}$ dan $\mathrm{W} 2=73,575$ $\mathrm{N}$. Sedangkan gaya reaksi dari rangka adalah sebesar $\mathrm{RB}=99,35 \mathrm{~N}$ dan $\mathrm{RA}=$ 190,645 N. Oleh karena W1 < RA dan $\mathrm{W} 2<\mathrm{RB}$, maka perancangan dinyatakan aman.

\section{g. Kapasitas Mesin Pemotong Kertas}

Kecepatan rol pemotong sebesar $30 \mathrm{rpm}$ dengan bahan uji yang digunakan adalah jenis kertas HVS A4 $(210 \times 297 \mathrm{~mm})$ 
dengan berat per-lembar sebesar 4,61 gram. Kertas dapat terpotong sepenuhnya dengan 2,5 kali putaran rol pemotong. Jumlah kertas yang terpotong selama 1 menit adalah 12 kertas dengan berat 55,32 gram, maka berat kertas dalam 1 jam sebesar 3319,2 gram x3 lembar adalah $10 \mathrm{~kg}$.

\subsection{Sketsa Gambar}

Mesin pemotong kertas ini dirancang dan dibuat dengan ukuran panjang 0,6 m, lebar 0,4 $\mathrm{m}$, dan tinggi 0,4 $\mathrm{m}$. Rangka mesin pemotong kertas ini terdiri dari 2 bagian, yaitu rangka atas yang berfungsi sebagai dudukan motor listrik, gear box, dan rol pemotong, kemudian rangka bawah yang berfungsi sebagai kaki pada rangka tersebut.

Dari hasil perhitungan di atas maka didapatkan hasil perancangan mesin pemotong kertas sesuai dengan rancangan seperti terlihat pada gambar 9.

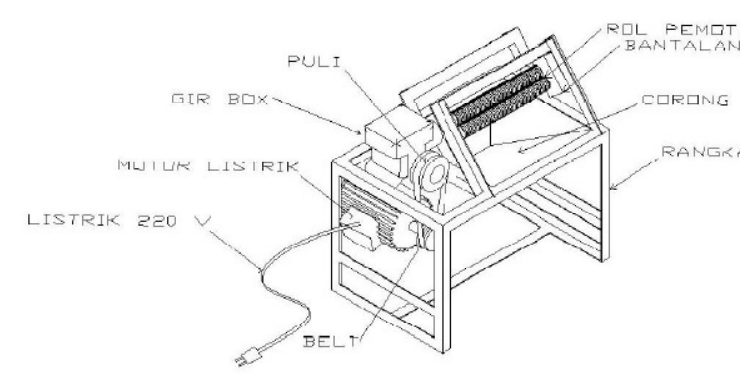

Gambar 9. Gambar rancangan mesin pemotong

\section{KESIMPULAN DAN SARAN}

\subsection{Kesimpulan}

Berdasarkan hasil perancangan dan perhitungan mesin pemotong kertas tipe pemotongan lurus, maka dapat disimpulkan sebagai berikut :

a. Untuk memperoleh mesin dengan kapasitas pemotongan sebesar $10 \mathrm{~kg} / \mathrm{jam}$ maka diperlukan daya motor $450 \mathrm{~W}$ dengan putaran 1400 rpm, puli penggerak sebagai penerus daya dengan perbandingan diameter $50 \mathrm{~mm}$ sedangkan puli yang digerakkan berdiameter $75 \mathrm{~mm}$ dan perbandingan gearbox (speed reducer) $1: 30$.

b. Berdasarkan hasil perhitungan, rangka mesin mampu menerima tegangan lentur yang diizinkan sebesar $50 \mathrm{~N} / \mathrm{mm} 2$, sedangkan beban sebenarnya yang diterima oleh rangka mesin adalah sebesar 250,155 $\mathrm{N}$ sehingga timbul tegangan lentur sebesar 44,6 N/mm2.
Jadi berdasarkan perhitungan tersebut maka rangka mesin dinyatakan aman dan layak untuk digunakan.

\subsection{Saran}

Berdasarkan hasil perancangan dan pembuatan mesin pemotong kertas maka disarankan sebagai berikut :

1. Sudut kemiringan rol pemotong di desain ulang kemiringannya menjadi 450, agar proses pemotongan kertas berlangsung lebih lancar.

2. Untuk menghindari terjadinya slip, maka penerus daya sebaiknya menggunakan roda gigi dan rantai.

3. Untuk memperoleh rancangan yang ideal antara rangka dengan beban yang ditumpu, maka jenis material rangka yang diabaikan harus dihitung berdasarkan spesifikasi data yang sesuai standar.

\section{REFERENSI}

1. Sularso, "Dasar Perencanaan dan Pemilihan Elemen Mesin", Pradnya Paramita, Jakarta 1978

2. Shigley (terjemah : G. Harahap), "Perencanaan Teknik Mesin", Erlangga, Jakarta 1991

3. Sularso, "Dasar Perencanaan dan Pemilihan Elemen Mesin", Pradnya Paramita, Jakarta 1994

4. Khurmi, R.S. and Gupta, J.K, "A Text of Machine Design", Ram Nagar, New Delhi 1982

5. Sonawan, Hery "Perancangan Elemen Mesin”, Alfabeta, Bandung 2010

6. Ikhsan, Aulia "Tugas Akhir Perancangan Sistem Penggerak Mesin Pengupas Buah Kenari Kapasitas $5 \mathrm{~kg} / \mathrm{jam}$ ", Universitas Nasional, Jakarta 2014

7. Kurnia, Indra "Tugas Akhir Rancang Bangun Mesin Pengiris Ubi Kapasitas 600 kg/hari”, Universitas Nasional, Jakarta 2006

8. SNI 07-2054-2006 